\title{
Policing Rio de Janeiro
}




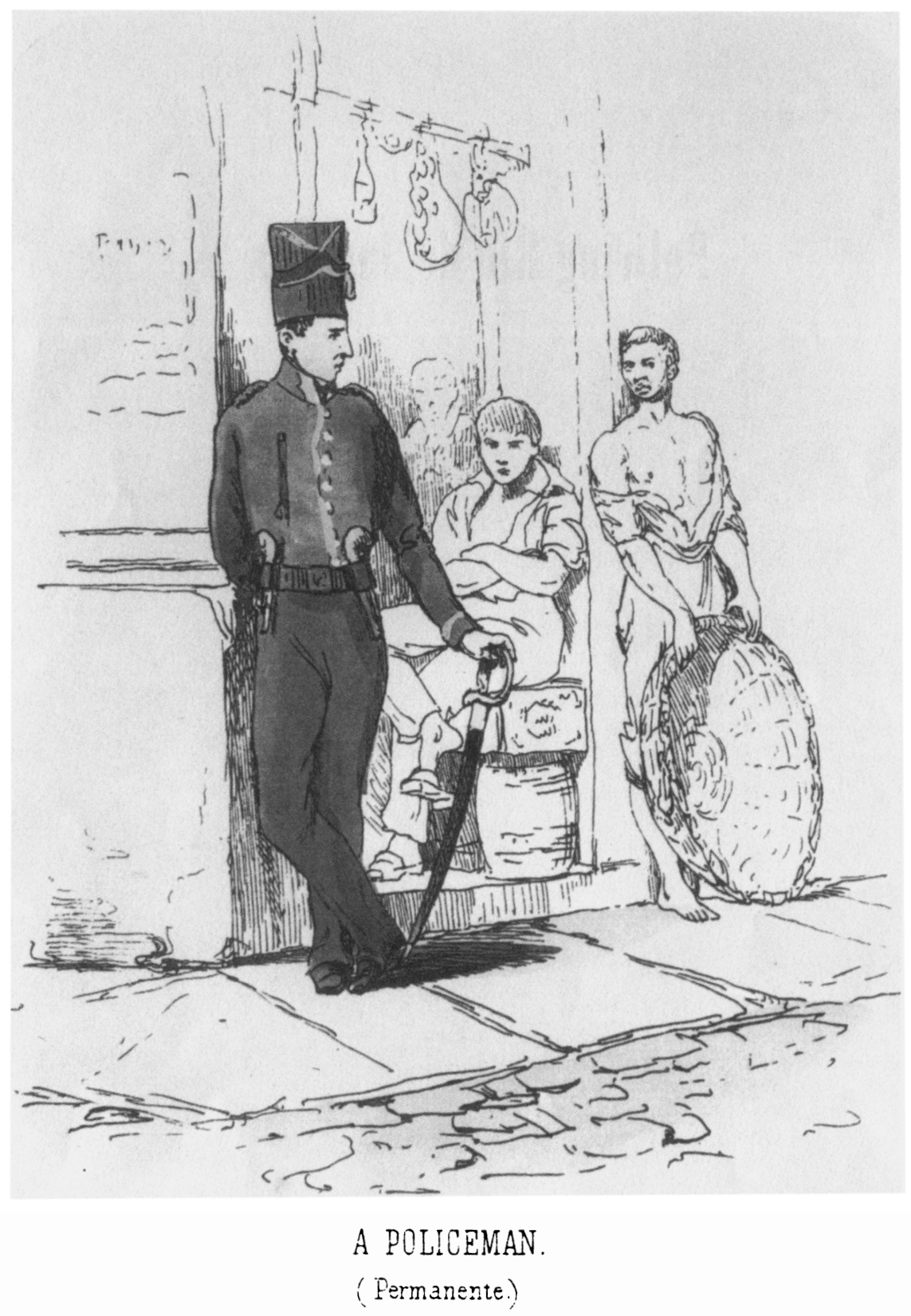



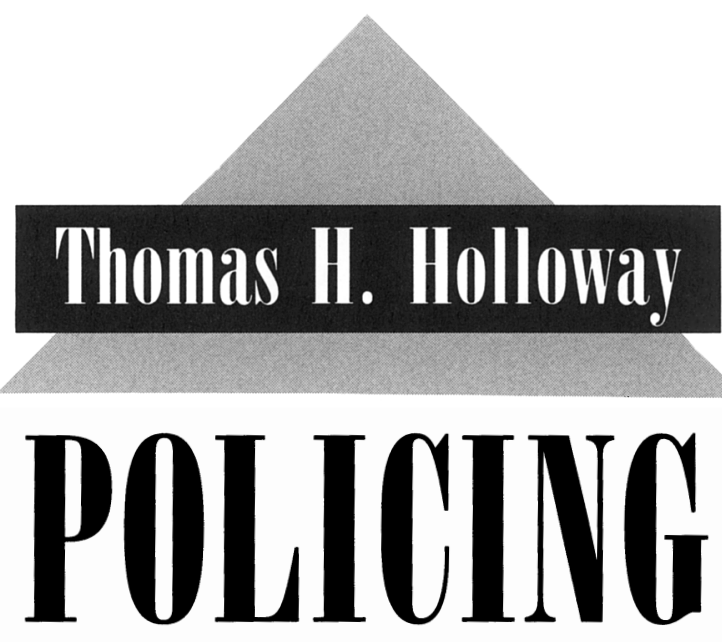

Rio de Janeiro

Repression and Resistance

in a 19 th-Century

City

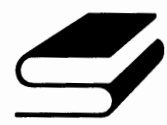

Stanford University Press

Stanford, California

1993 
Stanford University Press

Stanford, California

(C) 1993 by the Board of Trustees of the

Leland Stanford Junior University

CIP data appear at the end of the book

FRONTISPIECE: Lithograph from a collection by the Ludwig and Briggs studio in Rio de Janeiro, $1846-49$.

From Briggs, The Brasilian Souvenir.

Published with the assistance of the

Hull Memorial Publication Fund

of Cornell University 
To the people of Rio de Janeiro, who have resisted. 
